\title{
Quality Audit and Operational Excellence in Aviation Industry
}

\section{Abdullah Alshehri* and Vijaya GS}

College of Business Administration, Al Yamamah University, Kingdom of Saudi Arabia

\begin{abstract}
The purpose of this research is to identify the associated relationship between the auditing in aviation industry and its overall performance. The phases explored are the skills and techniques required and its contribution toward the operational excellence. This research uses a literature review; analysis of aviation professional's survey. As a result the Quality Audit is a major contributor towards the operational excellence.
\end{abstract}

Keywords: Quality audit; Operational excellence; IOSA; Surveillance; Aviation industry; IATA

\section{Introduction}

The aviation industry Airlines, airport operators, airport on-site enterprises (restaurants and retail), aircraft manufacturers, and air navigation service providers employed 100,000 people in Saudi Arabia in 2014. The air transport industry is estimated to have supported a $\$ 19.8$ billion gross value added contribution to GDP in Saudi Arabia in 2014. Spending by foreign tourists supported a further $\$ 14.5$ billion gross value added contribution to the country's GDP. This means that 4.6 percent of the country's GDP is supported by the air transport sector and foreign tourists arriving by air (IATA: Importance of Air Transport in Saudi Arabia).

Thus, the current study aimed at defining and exploring the constructs of aviation industry auditing and operational excellence along with the relationship between them. Primary and secondary data sources were utilized for the study. Relevant researches were selected and added to the literature. The survey was chosen to be applied for this study involving a survey questionnaire to be responded by experienced airline operators so as to meet our objectives. The results of the study emphasized on the significance of auditing on operational excellence in the airline industry. It was found that quality auditing has got significant importance when it comes to the airline industry. Findings reveal that the companies must be more involved in auditing regularly and the companies involved in auditing are more successful. Moreover, it was found that inter-company audits be made a standard to be in the airline industry and the operations must be changed on the basis of findings of auditing results. Additionally, audits were found to be adding value to airline operations. Furthermore, the results also show that implementation and documentation of quality audits are of vital importance for the airline industry.

\section{The Research Methodology}

The method used to conduct this research involves exploratory descriptive, reviewing of the literature, which involves reviewing of various researchers and extracting relevant information from them to answer the research question. The researchers were selected from various electronic databases. The researchers related to the focus topic "Quality audit and operational excellence in Aviation Industry" were included in this review. The review presented specifically focused on researchers that determined the outcomes of quality audits on airline operations, providing a neutral and structured paper. After the researchers were selected to be included, this was analyzed decisively and only valid and relevant research findings were included. Keywords used for gathering the relevant data and literature included auditing, quality audit, airline industry, operational excellence, TQM, and airline safety.
A questionnaire was also formulated with an aim to get an idea about the objectives of this study. The questions included in that questionnaire were validated by Aviation professionals and experts Aviation auditors. The data from those questionnaires were then gathered, and statistical analysis to reach consolidates results, conclusion, and discussion.

The data were collected based on various resources, locally and international resources are incorporated as a result of the nature of aviation industry which is global. The following elaborate more on data collection mechanism:

1. Primary data sources: A set of questionnaires that tested the practicality of implementing defined Standards and Recommended Practices (ISARPs) located in the IOSA However, this questionnaire were answered by aviation professionals and aviation auditors. Standards to achieve operational excellence in terms of improving safety, on-time performance, business process, overall control over operations cost...etc.

11. Secondary data sources: Many types of research and journals were evaluated and reviewed in order to present the literature and background of this study. These secondary data sources were utilized for this research by reviewing the findings of other researchers, reports, governmental organizations, companies... etc.

111. Interviewing aviation industry personnel: The interview of aviation Industry's professionals was to confirm that the research data to identified the importance of quality audit and other operations surveillance are well consolidate. The interview approach was to through unstructured interviewing methods where the research objective explained and the interviewee given the ground to give their opinion.

\section{Research objective}

The purpose of research is to discover answers to the questions through the application of the scientific procedure. The main aim of the research is to find out the authentic experience of aviation industry

*Corresponding author: Abdullah Alshehri, College of Business Administration, Al Yamamah University, Kingdom of Saudi Arabia, Tel: +12024459907; E-mail: 201711075@yu.edu.sa

Received September 08, 2018; Accepted October 11, 2018; Published October 21, 2018

Citation: Alshehri A, Vijaya GS (2018) Quality Audit and Operational Excellence in Aviation Industry. J Bus Fin Aff 7: 355. doi: 10.4172/2167-0234.1000355

Copyright: $\odot 2018$ Alshehri A, et al. This is an open-access article distributed under the terms of the Creative Commons Attribution License, which permits unrestricted use, distribution, and reproduction in any medium, provided the original author and source are credited. 
personnel. The research objectives as falling into a number of the following grouping:

1. To define the terms of the audit with reference to the aviation industry in the light of scientific literature.

2. To explore the research evidence, present on auditing and operational excellence in the aviation industry.

3. To critically investigate the relationship between quality audits and various airline operations.

4. To emphasize the importance of "documented" and "implemented" of procedures and policy by an Operator to ensure standardized application within its operational disciplines.

\section{Hypotheses}

- Hypothesis 1: Quality audits have significant importance in the aviation industry.

- Hypothesis 2: Quality audits directly influence the functioning of the Airline Industry.

- Hypothesis 3: The audit report result must be disclosed and shared with the aviation industry.

\section{Literature Review}

Quality Audits basically refer to a reliable process of evaluation that focuses on the performance of a certain company on various aspects of an industry [1]. These results, in turn, assist the stakeholders in making changes in strategies to improve the conditions of the company.

TQM is an umbrella term used to include in itself multiple aspects of quality. Juran and Gryna defined TQM as arranging and structuring activities in order to approach more buyers, satisfied workers, greater profits, and reduced expenses [2]. It was assumed by Juran that the reasons for a company's failure are related to management malpractices, rather than employee's fault. For raising the quality standards of a company, set of activities are needed to be done, these involve evaluating quality, improved quality management, application of statistical tools for calculation purpose, and viable benchmarking.

TQM emphasizes on the duties and accountabilities of management that involves commitment, governance, enablement, accreditation, reinforcement, and other related technical and man-based assistances. TQM specifically promotes the strategic assessments, skills of workers and educating them. TQM requires the management to recognize and reinforced the worker's individual struggles. TQM also focuses on paying attention towards products' design and specifically focuses on prevention of undesirable outcomes rather than working on assessment after undesirable outcomes [3].

Nowadays, the buyers' satisfaction in the airline industry has gained significant importance. With the introduction of new airlines, the competition among them has also increased and all the airlines strive hard to gain buyers' satisfaction by evaluation and improving the service quality [4]. Ostrowski et al. [5] researched and found that the airlines offering same fares and packages, the airline that is perceived to be providing better service by buyers' gets preference over the other airlines [6].

With the advancements in technology and safety tools, the traditional safety measures have lost their productivity. The raised demands of buyers with respect to safety in airlines have highly highlighted the safety concerns in the airline industry. The airlines internally keep checks of safety to maintain standards as well as safety has gained an integrated value, which has made it process oriented [6]

With the global development, air trafficking is also becoming multifaceted day by day. The airline's companies have to follow the safety measures in order to function properly; otherwise, get banned from the market, limiting their scope for the whole life [6].

There are two types of audits done in the airline industry. One is an inter-airline audit, which assesses the objective information regarding a certain airline company, through utilizing various tool i.e. interviews, company's records etc. It specifically focuses on the company, eliminating the blame game to the workforce. On the other hand, the second type of audit is authority audits, in which the authorities keep a check and balance and evaluate either the operations of the company are aligned with the company's regulations or not [6].

Auditing of airline involves evaluation of safety, fare management, customers' satisfaction, assessment of machinery and equipment, the condition of air crafts, runway evaluation etc. Auditing is not only restricted to guarantee the quality standards, it also focuses on identifying the weaknesses of aviation industry or certain airlines in order to improve those aspects. It provides the managers the feedback on program execution that in turn assists them in making future decisions [7].

The literature-based research to find out the process of designing and executing the strategic plan in the airline industry. The results of the study concluded that in order to function efficiently, the airlines have to plan a strategy, position the plan appropriately, operational execution and assessment, which involves auditing, either internal or external and lastly regulating the program. In this way, auditing of the certain program can result in making structural and strategic improvements in an airline program already introduced. The study's scope was limited because it only utilized secondary data sources and no specific airline data was analyzed.

Quality audits are done in a way to improve the operations of the airlines. Several companies have been founded that provides audit services on international levels to keep up the quality standards, for example, IATA Operational Safety Audit (IOSA), which is one of the most standardized assessment system utilized internationally in the aviation industry for evaluating functioning, administration and control systems of registered airlines [8,9]. IOSA is an International Organization for Standardization (ISO) certified standard of evaluation, which included in itself 8 major quality management principles i.e. process approach, system approach to manging, accurate approach to decision-making, leading the industry personnel, involvement of people, jointly beneficial supplier relationship, customer focus, continual improvement [10]. Both the ISO 9001 and IOSA follow same eight quality management values, however, IOSA is higher in terms of quality standards and operational safety of concerned airlines in various aspects [10]. In the same way CAA (Civil Aviation Authority) also conducts audits in many countries to make enhancements in program implementation. In the same way CAA (Civil Aviation Authority) also conducts Audits, Surveillance, and Random Inspections in many countries to make enhancements in industry compliance.

Airsight publishes that audits are of vital importance for stakeholders for implementing systems [11]. Thomas researched and found that the airlines that have accredited safety management audits were less likely to undergo accidents. Kin researched and proved the same findings that there exists a negative association between safety management audits and number of accidents [12]. It also stated that 
there exists a strong association between the number of audits directed and the number of audit results.

Kin researched to find the impact of various audits on the airline operations and found a positive association between safety management audits and ground handling. In the same way, a positive correlation was observed between safety management audits and airworthiness [12]. McDonald et al. opined that the cause of every airline mishap is an unsuccessful administration and a strong need for safety management audits to discourse air safety [13].

The operations audit is based on industry-proven quality audit principles and is formulated to ensure that each Audit is executed in a standardized methodology to achieve consistent outcomes.

Audit standards developed for overall evaluation of the airline's firm for assessing the operational management and quality system. The questionnaire of this research was developed to assess the main objectives. The industry's expertise was participated to contribute answering the importance of quality audit is related to the research objectives.

\section{Findings and Analysis}

The result of the search's survey are summarized as follows:

$\checkmark$ Quality audit contributes to improving safety performance and reduces the number of redundant audits performed among organization and airline's partners.

$\checkmark$ Promote the audit principle and emphasize on operational management and control system.

$\checkmark$ The study shows that about $84 \%$ of the aviation industry agrees on the significant importance of the quality audit in the aviation industry. The more audit to be conducted are more successful comparing to the previous decade. All are agreed that the CAA must be involved in helping airlines by conducting more audit and surveillance comparable to the size and complex ability of the company (Figure 1).

The previous analysis was conducted based on aviation factual data elaborate on the Quality and Safety audit had a tremendous impact on decreasing the accident in the aviation industry. The following chart will elaborate on the importance being IOSA certified comparing to non-IOSA members and how this reduced the risk of fatality accident per million flights for the study period of 2012 till 2017 (Figure 2).

\section{Conclusion}

Overall, the study was aimed to explore and define the terms of the audit with reference to the aviation industry in the light of scientific literature. The finding of the survey suggests that quality audit has got significant importance in the aviation industry; the company must subscribe itself to an external auditing company. The results also suggest that companies doing more research are more successful as compared to other companies and that the authorities (CAA) must be doing more audits on airlines on a regular basis. The results of the research are consistent with previous literature $[7,11,14]$.

\section{References}

1. Furubo JE (2011) Performance Auditing: Audit or misnomer? In Lonsdale

\section{Quality Audit Survey}

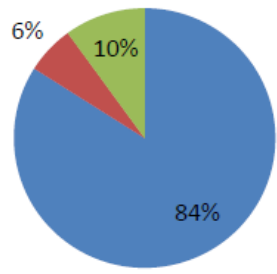

Agree of Importance of Quality Audit

Not Agree

Agree up on International Standards

Figure 1: Quality audit in the aviation industry.

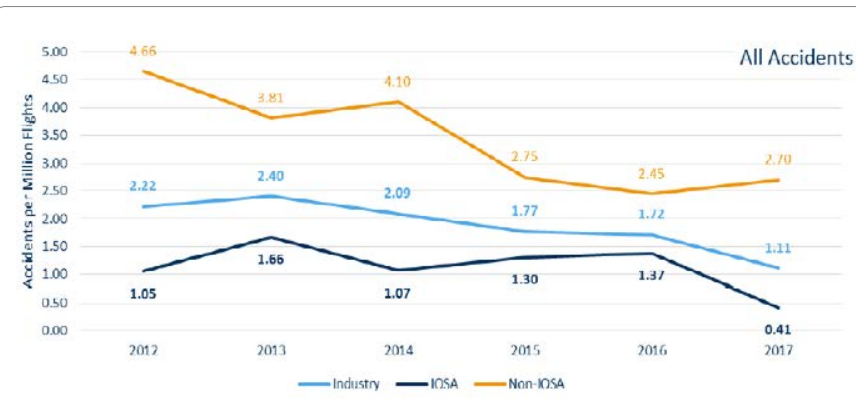

Figure 2: Risk of fatality accident per million flights.

J, Wilkins $\mathrm{P}$ and Ling $\mathrm{T}$ (Eds), Performance Auditing: Contributing to Accountability in Democratic Government. Edward Elgar Publishing Limited, Cheltenham, pp: 22- 50 .

2. Juran JM, Gryna FM (1988) The quality control handbook. (4th ed), McGrawHill, New York.

3. Aole RM, Gorantiwar VS (2013) Quality gurus: Philosophy and teachings. Int J Res Aeronaut Mech Eng 1: 46-52.

4. Dennet CE, Ineson M, Stone GJ, Colgate M (2000) Pre-bookable Services in the Chartered Airline Industry: Increasing Satisfaction through Differentiation. The Service Industries J 20: 82-94.

5. Ostrowski RL, O’Brien TV, Gordon GL (1993) Service quality and customer loyalty in the commercial airline industry. J Travel Res 32: 16-24.

6. Fakles D, Steiner S (2004) IATA Operational Safety Audit (IOSA) in function of safety.

7. Joint Aviation Authorities (2013) Quality management - Principles \& practice in an aviation environment.

8. IATA (2016) Annual review.

9. IOSA fact sheets.

10. Deb S (2007) Airline safety standard exceeds ISO 9001. Aerosafety world.

11. Airsight (2017) Auditing in aviation

12. Kin RYC (2015) The impact of safety management systems on safety performance: Commercial aviation operations.

13. McDonald N, Corrigan S, Daly C, Cromie S (2000) Safety management systems and safety culture in aircraft maintenance organizations. Safety Science 34: 151-176.

14. Ahmed AM (2008) Create superior customer values: a new direction for Middle Eastern airlines. Education, Business, and Society: Contemporary Middle Eastern Issues 1: 287-299. 